\title{
MATHEMATICAL MODELING FOR PREDICTING ANGULAR DISTORTION IN TIG WELDING OF STAINLESS STEEL 409L BUTT WELDS
}

\author{
Ishika Aggarwal $^{1}$, Nimeshka Faujdar ${ }^{2}$, Anusua Das ${ }^{3}$, Pradeep Khanna ${ }^{4}$ \\ ${ }^{I}$ Student, Manufacturing Processes \& Automation Engineering Department, NSIT, New-Delhi, India \\ ${ }^{2}$ Student, Manufacturing Processes \& Automation Engineering Department, NSIT, New-Delhi, India \\ ${ }^{3}$ Student, Manufacturing Processes \& Automation Engineering Department, NSIT, New-Delhi, India \\ ${ }^{4}$ Associate Professor, MPAED, NSIT, New-Delhi, India
}

\begin{abstract}
TIG welding process has increasingly been used in the fabrication of ferrous and non-ferrous materials alike owing to its adaptability and ease of welding any known weldable material. The process also lends itself to automation, making it ideal for mass manufacturing industries. When automated, it can successfully weld autogenous joints. The process is largely used to weld thin gauge sheets. The present work is aimed to investigate the effects of controllable input parameters like welding current, welding speed and torch angle on the response parameters which is angular distortion of the resulting weldments in this case. An attempt has also been made to develop a mathematical equation relating input parameters to the response so that an optimized setting of these parameters can be obtained to have minimum possible angular distortion. Central composite face centered technique has been used to developed the mathematical model, whose adequacy has been tested by ANOVA analysis. Significance of the regression coefficients has been tested by t-test. Response Surface Methodology has been used for optimization of the developed model.
\end{abstract}

Keywords: - Autogenous, automation, response surface methodology, optimization, mathematical modeling.

\section{INTRODUCTION}

Tungsten inert gas welding, TIG is widely used in manufacturing process for different types of materials like Aluminum, Mild steel and different type of stainless and alloy steels. The optimization of TIG welding process parameters play important role for the final product quality in terms of weld distortions, joint efficiency and mechanical properties. As welding process involves the heating and cooling process in non-uniform manner, the distortions are unavoidable. The weld process contributes to the development of several kinds of distortions like longitudinal, transverse or angular distortion [1]. Every effort should be made to keep these distortions minimum as they not only spoil the esthetics of the joint but also result in dimensional deviations causing misfits in the final assembly. The present work is aimed at investigating the effects of input process parameters on angular distortion (fig.1). An elaborated experimental work has been carried out to evolve a mathematical model which might help in correctly selecting the process parameters so as to have minimal angular distortion. The material selected for present investigation work is stainless steel 409L which is a newly developed low carbon variant of stainless steel. The material has good workability and because of the less amount of carbon has reasonably good weld ability with less chances of cracking and material also possess good inter-granular corrosion resistance [2, 3]. Literature survey has also revealed that not much experimental work has been conducted on material so far. This makes a strong base for conducting experiments on this material. The chemical properties on material are given in table-1 and distinctive mechanical and physical properties of the material are given in table- 2 .

An elaborated experimental work was carried out with the selected input parameters by using statistical technique of using design of experiments (DOE).

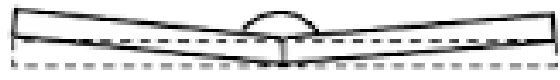

Fig 1: Angular Distortion [2]

Table 1: Chemical composition of Stainless Steel 409L

\begin{tabular}{|l|l|l|l|l|l|l|l|}
\hline Element & C & Mn & P & S & Si & Cr & Ni \\
\hline $\begin{array}{l}\text { Max } \\
\text { percentage }\end{array}$ & $\mathbf{0 . 0 3}$ & 1 & $\mathbf{0 . 0 4}$ & $\mathbf{0 . 0 3}$ & $\mathbf{1}$ & $\begin{array}{l}10.5- \\
\text { 11.7 }\end{array}$ & 0.5 \\
\hline
\end{tabular}

Table 2: Physical and Chemical properties of 409L

\begin{tabular}{|l|l|l|l|}
\hline \multicolumn{4}{|l|}{ Mechanical Properties } \\
\hline $\begin{array}{l}\text { Yield } \\
\text { Strength } \\
\left(\mathbf{N} / \mathbf{m m}^{2}\right)\end{array}$ & $\begin{array}{l}\text { Tensile } \\
\text { Strength } \\
\left(\mathbf{N} / \mathbf{m m}^{2}\right)\end{array}$ & $\begin{array}{l}\text { Elongation } \\
(\%)\end{array}$ & $\begin{array}{l}\text { Hardness } \\
(\mathbf{H v})\end{array}$ \\
\hline$\geq \mathbf{1 7 5}$ & $\geq \mathbf{3 6 0}$ & $\geq \mathbf{2 5}$ & $\leq \mathbf{1 7 5}$ \\
\hline
\end{tabular}




\begin{tabular}{|l|l|l|l|}
\hline \multicolumn{3}{|l|}{ Physical Properties } \\
\hline $\begin{array}{l}\text { Specific } \\
\text { Heat } \\
\left(\mathrm{J} / \mathrm{g}^{\circ} \mathrm{C}\right)\end{array}$ & $\begin{array}{l}\text { Specific } \\
\text { Gravity }\end{array}$ & $\begin{array}{l}\text { Thermal } \\
\text { Expansion } \\
\text { Coefficient } \\
\left(\mathrm{W} / \mathrm{m}^{\circ} \mathrm{C}\right) \\
\left(20-100^{\circ} \mathrm{C}\right)\end{array}$ & $\begin{array}{l}\text { Thermal } \\
\text { Conductivity } \\
\left(\mathrm{W} / \mathbf{m}^{\circ} \mathrm{C}\right) \\
\left(100^{\circ} \mathrm{C}\right)\end{array}$ \\
\hline $\mathbf{0 . 4 6}$ & $\mathbf{7 . 7 5}$ & 6.5 & $\mathbf{2 4 9}$ \\
\hline
\end{tabular}

\section{WELDING SETUP}

The welding experimentation was conducted on a welding power source of current rating of 200A. In order to achieve the reproducibility in results, the practicals were conducted on a mechanized welding carriage where the torch was attached to a radial rotating arm which had the arrangement of moving up-down and across the table. The table of the system was driven by a motor and gear box arrangement with a variable frequency drive to have stepless control of speed from $0 \mathrm{~cm} / \mathrm{min}$ to $50 \mathrm{~cm} / \mathrm{min}$. The setup is shown in figure 2.

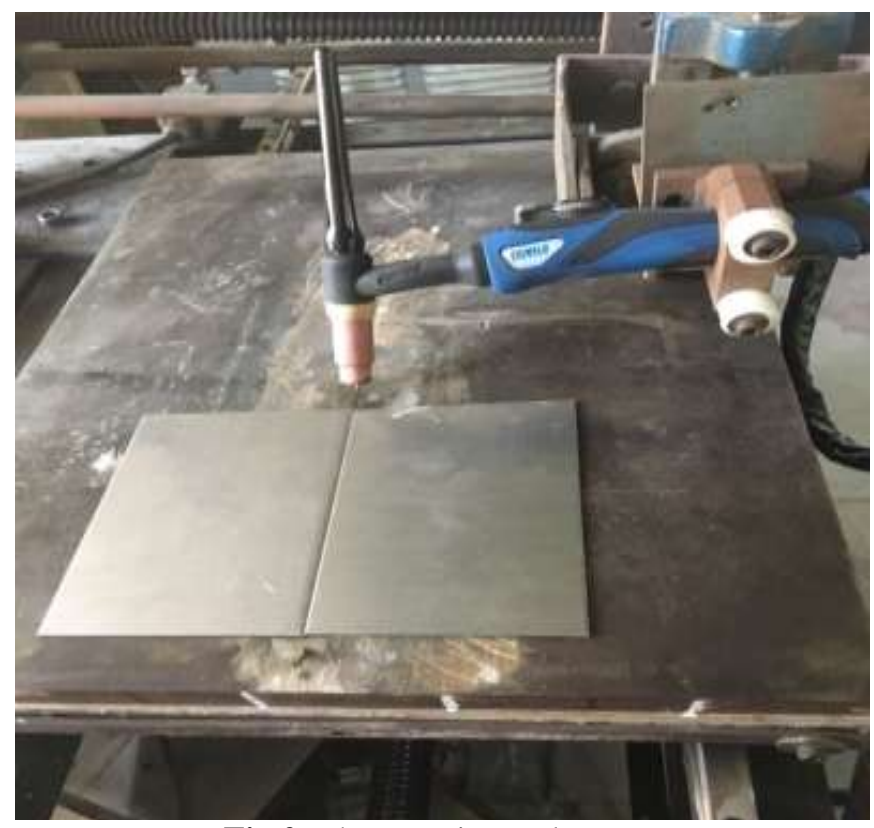

Fig 2: The experimental setup

\section{PLAN OF INVESTIGATION}

\subsection{Identification of Important Welding Parameter and Establishing their Working Limits-}

On the basis of trial runs conducted, it was found that the angular distortion was dependent on primarily welding current, welding speed and torch angle. Several trial runs were conducted to know the working of lower and upper limits of these independently controllable variables on the basis of following observations:

1 Appearance of bead is uniform

2 No over penetration

3 No overlapping of the plates
The limits of the parameters are given in the table 3

Table -3: Welding Parameters with limits

\begin{tabular}{|l|l|l|l|r|r|}
\hline Factor & \multicolumn{1}{|c|}{ Name } & Units & Type & Minimum & Maximum \\
\hline A & Weldinq Current & Amperes & Numeric & 80.00 & 120.00 \\
\hline B & Weldinq Speed & $\mathrm{Hz}$ & Numeric & 20.00 & 40.00 \\
\hline C & Torch Anqle & Degrees & Numeric & 45.00 & 90.00 \\
\hline
\end{tabular}

\subsection{Development of Design Matrix}

In the present investigation central composite face centered technique has been used to develop a design matrix with 20 number of experimental run $\left(2^{\wedge} 3+2 * 3+6=20\right) . \quad 2^{\wedge} 3=8$ represents the center points. $2 * 3=6$ represents the star points and additional 6 runs have been added, all at zero levels of parameters to improve the precision of model. The experimentation is conducted in one replicate and 20 numbers of experiments were run as per the design matrix shown in table 4 .

Table 4 : Runs as per design matrix

\begin{tabular}{|r|r|r|r|r|r|r|}
\hline Std & Run & $\begin{array}{c}\text { Factor } 1 \\
\text { A.Welding Curre... } \\
\text { Amperes }\end{array}$ & $\begin{array}{c}\text { Factor } 2 \\
\text { B:Welding Speed } \\
\text { Hz }\end{array}$ & $\begin{array}{c}\text { Factor } 3 \\
\text { CiTorch Angle } \\
\text { Degrees }\end{array}$ & $\begin{array}{c}\text { Response 1 } \\
\text { Distortion Length } \\
\text { mm }\end{array}$ \\
\hline 13 & 1 & 100 & 30 & 45 & 1.44 \\
\hline 8 & 2 & 120 & 40 & 90 & 1.43 \\
\hline 7 & 3 & 80 & 40 & 90 & 1.61 \\
\hline 9 & 4 & 80 & 30 & 67.5 & 7.35 \\
\hline 5 & 5 & 80 & 20 & 90 & 6.42 \\
\hline 19 & 6 & 100 & 30 & 67.5 & 6.34 \\
\hline 17 & 7 & 100 & 30 & 67.5 & 3.21 \\
\hline 12 & 8 & 100 & 40 & 67.5 & 4.14 \\
\hline 20 & 9 & 100 & 30 & 67.5 & 5.44 \\
\hline 18 & 10 & 100 & 30 & 67.5 & 4.15 \\
\hline 16 & 11 & 100 & 30 & 67.5 & 7.52 \\
\hline 11 & 12 & 100 & 20 & 67.5 & 5.38 \\
\hline 3 & 13 & 80 & 40 & 45 & 2.08 \\
\hline 6 & 14 & 120 & 20 & 90 & 12.6 \\
\hline 15 & 15 & 100 & 30 & 67.5 & 6.77 \\
\hline 2 & 16 & 120 & 20 & 45 & 8.17 \\
\hline 10 & 17 & 120 & 30 & 67.5 & 7.4 \\
\hline 14 & 18 & 100 & 30 & 90 & 3.04 \\
\hline 4 & 19 & 120 & 40 & 45 & 2.25 \\
\hline 1 & 20 & 80 & 20 & 45 & 6.12 \\
\hline & & & & & \\
\hline
\end{tabular}

\subsection{Conducting the Experiment as per Design}

\section{Matrix}

The runs were conducted in a randomized manner so that systematic error, if any in the system gets eliminated. The response parameter i.e. angular distortion of the weldments was measured using the setup shown in fig 3 . 


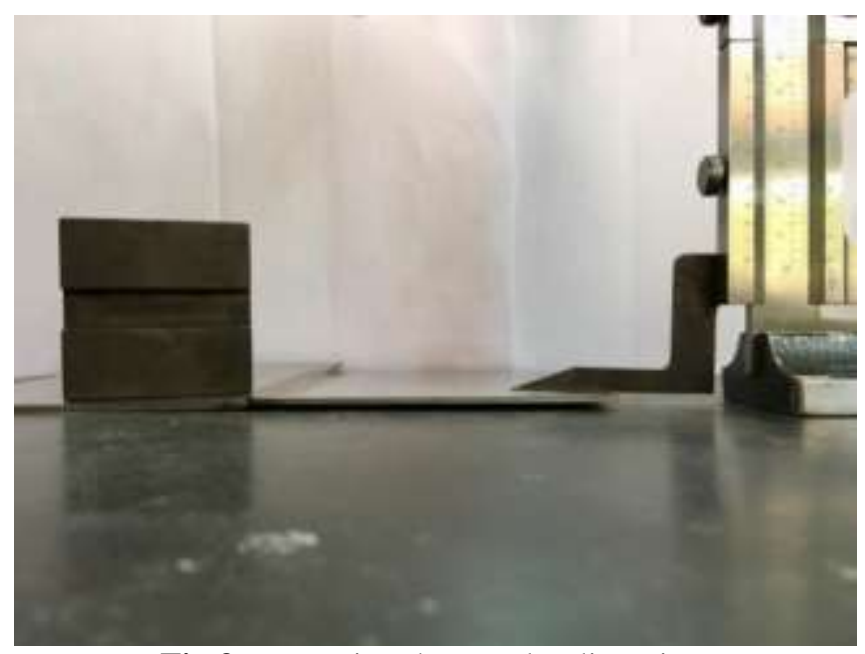

Fig 3: measuring the angular distortion

Two readings per weldments were taken with one reading at each edge and the average of the two was used to calculate angular distortions as per following relationship:

$$
\operatorname{Sin} \Theta=P / H
$$

The values of angular distortion are shown in table 4

\subsection{Development of Mathematical Model}

For the present investigation work statistical techniques of design of experiments was used. The general expression relating the input parameters to the response output can be expressed as follows

$$
f(\Theta)=(A, B, C)
$$

Where

$\Theta=$ angular distortion

$\mathrm{A}=$ welding current

$\mathrm{B}=$ welding Speed

$\mathrm{C}=$ torch angle

The general mathematical equation can be given as follows

$$
\Theta=\beta_{0}+\beta_{1} \mathrm{~A}+\beta_{2} \mathrm{~B}+\beta_{3} \mathrm{C}+\beta_{12} \mathrm{AB}+\beta_{13} \mathrm{AC}+\beta_{23} \mathrm{BC}+\beta_{11} \mathrm{~A}^{2}+\beta_{22}
$$

After putting the respective values in design expert software, the following mathematical equation was obtained in the coded form

Distortion angle $(\Theta)=+5.30+0.80 * \mathrm{~A}-2.72 * \mathrm{~B}+0.50 * \mathrm{C}$ $1.03 * \mathrm{AB}+0.47 * \mathrm{AC}-0.75 * \mathrm{~B} \mathrm{C}+2.48 * \mathrm{~A}^{2}-0.13 \mathrm{~B}^{2}-2.66 * \mathrm{C}^{2}$

\subsection{Checking the Adequacy of the Developed Model}

After putting all the values of response and input parameters into the design expert software following table was obtained which shows that the developed model is significant and the lack of fit is insignificant.
Table 5: ANOVA Analysis of the model

\begin{tabular}{|l|r|r|r|r|r|r|}
\hline Source & $\begin{array}{c}\text { Sum of } \\
\text { Squares }\end{array}$ & df & $\begin{array}{c}\text { Mean } \\
\text { Square }\end{array}$ & F-value & p-value & \\
\hline Model & 124.80 & 9 & 13.87 & 4.58 & 0.0131 & significant \\
\hline A-Welding Current & 6.84 & 1 & 6.84 & 2.26 & 0.1638 & \\
\hline B-Welding Speed & 73.88 & 1 & 73.88 & 24.40 & 0.0006 & \\
\hline C-Torch Angle & 2.54 & 1 & 2.54 & 0.8390 & 0.3812 & \\
\hline AB & 8.49 & 1 & 8.49 & 2.80 & 0.1250 & \\
\hline AC & 1.79 & 1 & 1.79 & 0.5899 & 0.4602 & \\
\hline BC & 4.53 & 1 & 4.53 & 1.50 & 0.2493 & \\
\hline A $^{2}$ & 16.88 & 1 & 16.88 & 5.57 & 0.0399 & \\
\hline B $^{2}$ & 0.0522 & 1 & 0.0522 & 0.0172 & 0.8982 & \\
\hline C $^{2}$ & 19.42 & 1 & 19.42 & 6.42 & 0.0297 & \\
\hline Residual & 30.28 & 10 & 3.03 & & & \\
\hline Lack of Fit & 16.84 & 5 & 3.37 & 1.25 & 0.4053 & not significant \\
\hline Pure Error & 13.44 & 5 & 2.69 & & & \\
\hline Cor Total & 155.08 & 19 & & & & \\
\hline
\end{tabular}

The $\mathrm{R}^{2}$ value of 0.8048 of the developed model as per the table 6 given below also shows reasonable adequacy of the model. This is further substantiated by the scattered diagram shown in figure 4 which shows closed proximity between actual and predicted values.

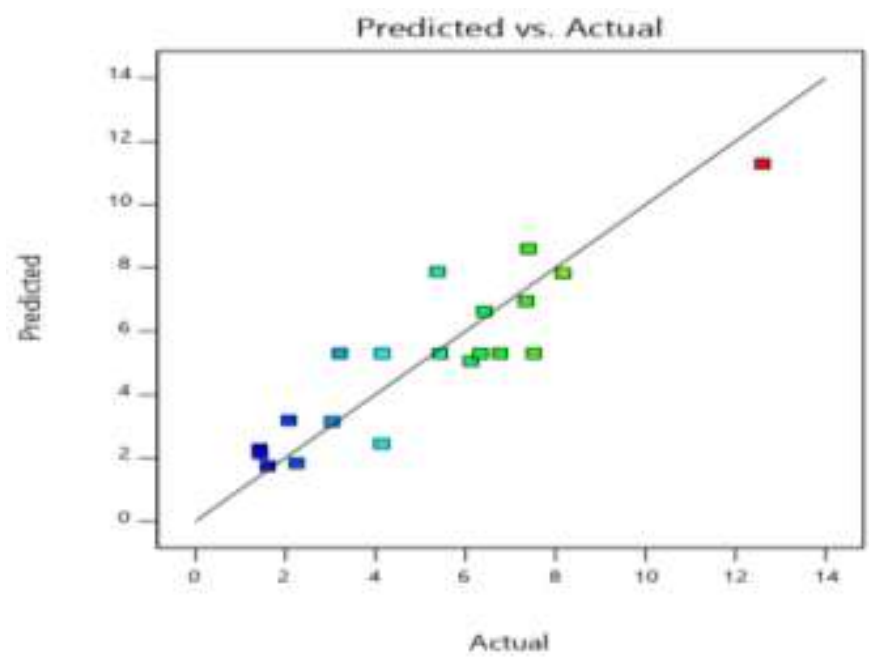

Fig 4: Scattered diagram for angular distortion

Table 6: Fit Statistics of the model

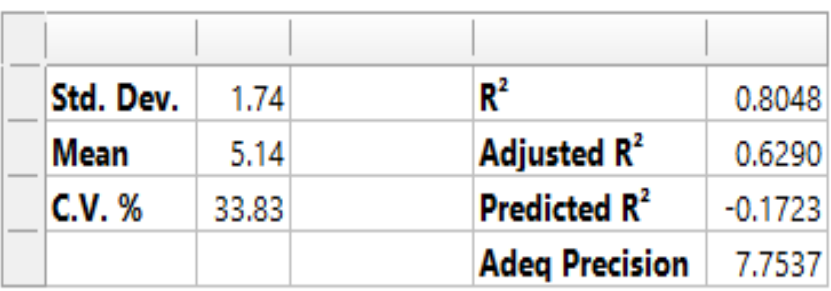

\section{RESULTS AND DISCUSSIONS}

The results obtained after statistical analysis are presented in chart (1-6).It was observed that there existed direct and indirection effects amongst the input parameters. These direct and interaction effects are discussed as below: 


\subsection{Direct Effects of Welding Parameters}

\subsubsection{Effect of Welding Current}

It has been observed from the figure 5 that there has been an increase in angular distortion from 7 degrees to 8.6 degrees with an increase in current from 80 to 120 amperes. The reason for this can be attributed to the fact that with the increase in welding current the heat input also increased resulting in deeper penetrations causing more angular distortions. There however existed a region between minimum and maximum value of currents in which the angular distortion was found to be decreased. The reason might be interaction effects of other welding parameters.

\section{Angular Distortion due to} welding current

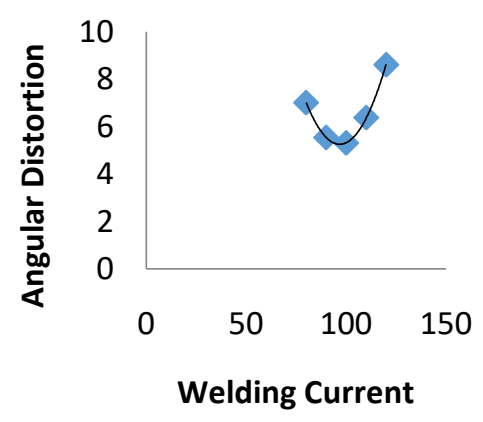

$\rightarrow$ Angular Distortion

Poly. (Angular Distortion)

Chart 1: Direct effect of welding current

\subsubsection{Effect of Welding Speed}

It has been observed from the figure 6 that there has been a decrease in angular distortion from 7.91 degrees to 2.47 degrees with an increase in speed from 20 to $40 \mathrm{~cm} / \mathrm{min}$. The reason for this can be attributed to the fact that at high welding speed, heat input will be low resulting in decrease in angular distortion. The interaction effects are negligible in case of welding speed.

\section{Angular Distortion due to Welding Speed}

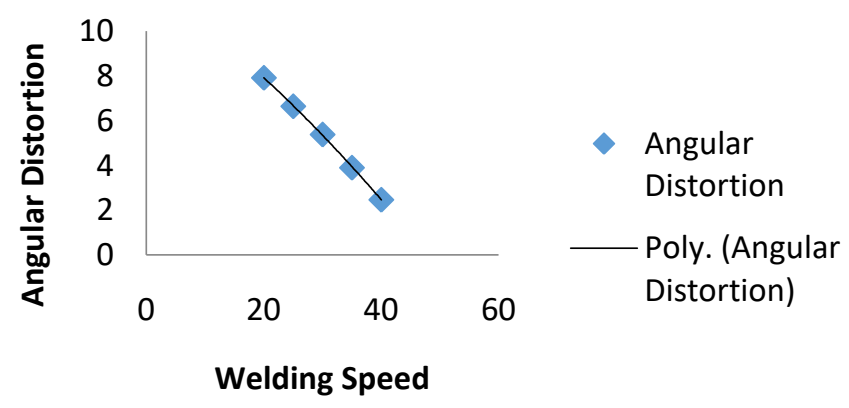

\subsubsection{Effect of Torch Angle}

It has been observed from the figure 7 that there has been an increase in angular distortion from 2.2 degrees to 3.02 degrees with an increase in torch angle from 45 to 90 degrees. The reason for this can be attributed to the fact that for steeper torch angle, the depth of penetration in the plate is slightly greater than that for a shallow angled torch. Thus, the heat amount input in the weld bead, giving non-uniform distribution leads to distortion which is more in steeper torch angle positions and less in shallow torch angle positions. There however existed a region between minimum and maximum value of currents in which the angular distortion was found to be first increased and then decreased. The reason might be interaction effects of other welding parameters.

\section{Angular Distortion due to torch angle}

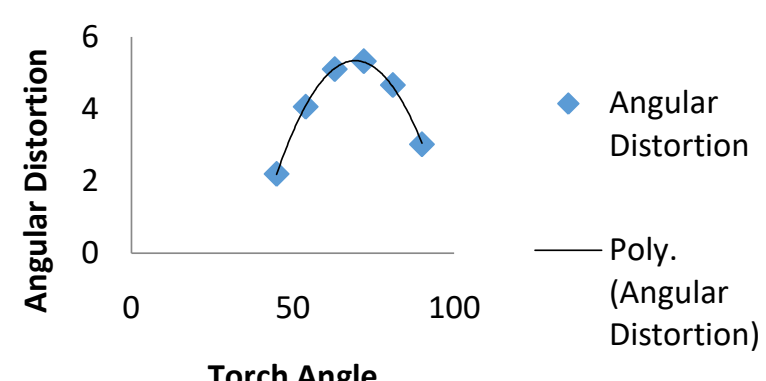

Chart 3: direct effect of torch angle

\subsection{Interaction Effects of Welding Parameters}

\subsubsection{Interaction Effect of Torch Angle and}

\section{Welding Speed}

As shown in figure 8, at all the values of welding speed, angular distortion increases initially, and then decreases with the increase of torch angle. This fact states the reason that for steeper torch angle, the depth of penetration in to the plate is slightly greater than that for a shallow angled torch. Thus, the heat amount input in the weld bead, giving nonuniform distribution leads to distortion which is more in steeper torch angle positions and less in shallow torch angle positions. At all the values of torch angle, angular distortion decreases with the increase of welding speed. Clearly, at high welding speed, heat input will be low resulting in decrease in angular distortion.

Chart 2: Direct effect of welding speed 


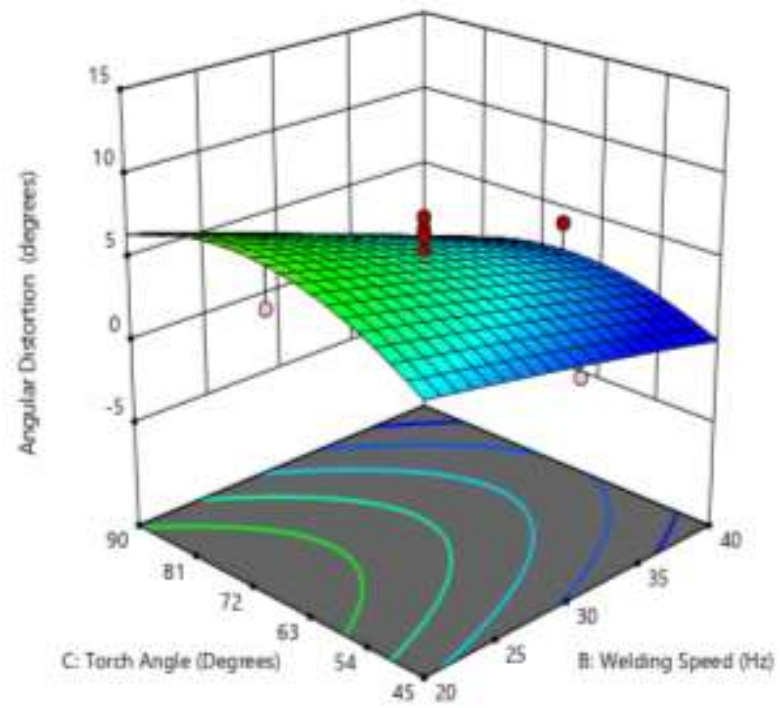

Chart 4: Interaction effect of torch angle and welding speed

\subsubsection{Interaction Effects of Welding Current and}

\section{Welding Speed}

As shown in figure 9, at all the values of welding current, angular distortion decreases with the increase in welding speed. Clearly, at high welding speed, heat input will be low resulting in decrease in angular distortion. At all the values of welding speed, angular distortion decreases initially, then increase with the increase in welding current. The reason for this fact states that on certain low welding current, the widening effect of the arc predominates and puts less heat into the joint resulting in the initial decrease of angular distortion. However the distortion increased after 100 amperes because at this high current the penetrating effects predominate over the widening effects resulting in increase in distortion.

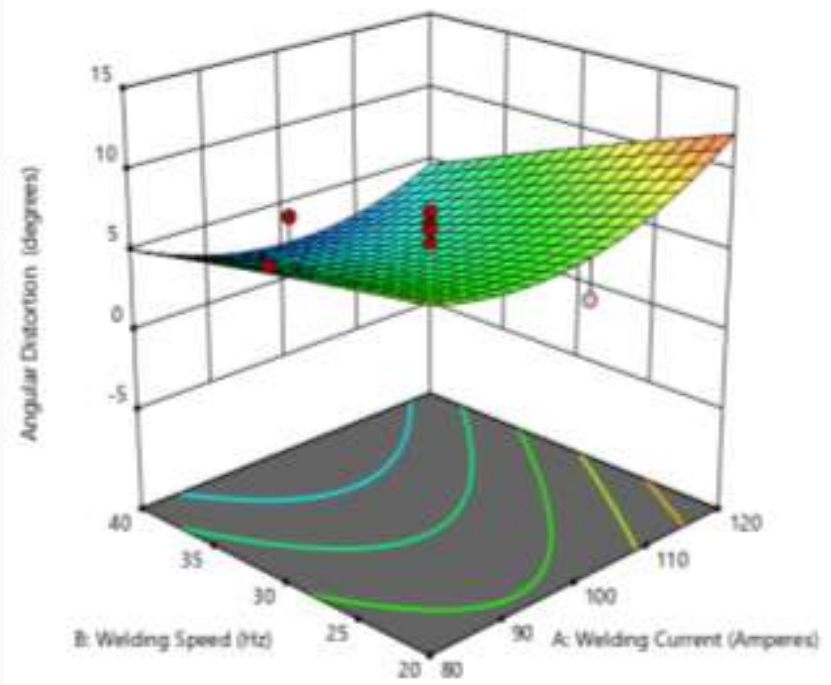

Chart 5: Interaction effect of welding current and welding speed

\subsubsection{Interaction Effect of Torch Angle and Welding Current}

As shown in figure 10, at all the values of welding current, angular distortion increases initially, and then decrease with the increase in torch angle. Clearly, at steeper torch angle, the angular distortion is more.

At all the values of torch angle, angular distortion decreases initially, and then increases with the increase in welding current. Clearly, at high welding current, heat input will be high resulting in increase in angular distortion.

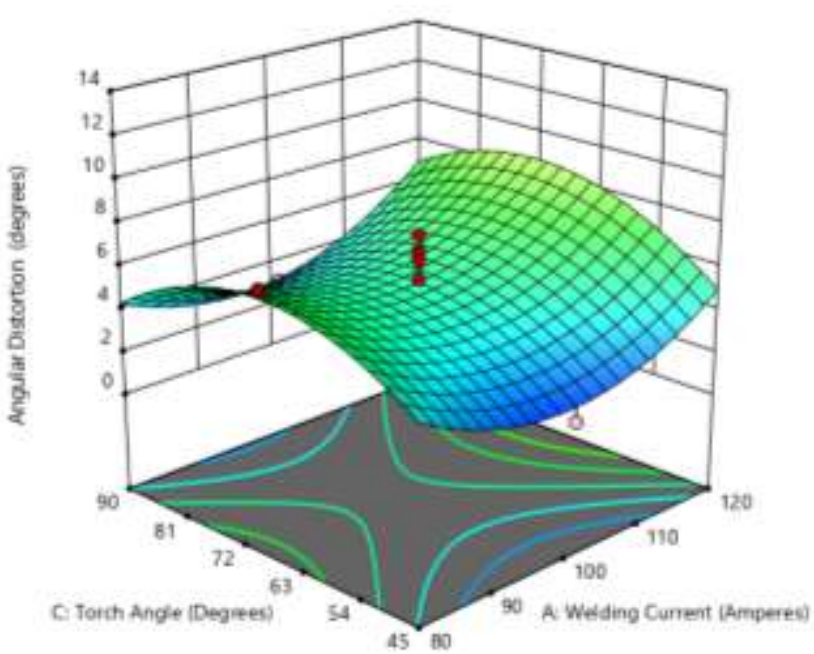

Chart 6: Interaction effect of welding current and torch angle

\section{CONCLUSION}

On the basis of experimental work carried out, following conclusions can be drawn

(1) Welding current has allover a positive effect on angular distortion

(2) Welding Speed has allover a negative effect on angular distortion

(3) Torch Angle has all over a positive effect on angular distortion

(4) At all the values of welding speed, angular distortion increases initially, and then decreases with the increase of torch angle

(5) At all the values of torch angle, angular distortion decreases with the increase of welding speed.

(6) At all the values of welding current, angular distortion decreases with the increase in welding speed.

(7) At all the values of welding speed, angular distortion decreases initially, then increase with the increase in welding current.

(8) At all the values of welding current, angular distortion increases initially, and then decrease with the increase in torch angle

(9) At all the values of torch angle, angular distortion decreases initially, and then increases with the increase in welding current 


\section{ACKNOWLEDGEMENT}

The authors are grateful to $\mathrm{M} / \mathrm{s}$. Jindal Stainless Pvt. Ltd. Gurgaon for their support in providing material for this investigation. The authors also extend theirthankfulness to $\mathrm{M} / \mathrm{s}$. United Engineering Corporation, Mayapuri andfinally to Mr. S. Prabhu, mechanic at welding shop NSIT, New Delhi.

\section{REFERENCES}

[1] Masubuchi K., "Control of Distortion and Shrinkage in Welding”, Bulletin of WRC, No. 149, pp.30, 1970

[2] Akella, S., Ramesh, K.B., "Distortion Control in TIG Welding Process with Taguchi Approach" Journal of Advanced Material Manufacturing and Characterization, Vol. 3, Issue 1, pp. 199-206, March 2013.

[3] Dinesh, K.R., Sooriyamoorthy, E., "Parametric Optimization of Pulsed - TIG Welding Process in Butt Joining of 304L Austenitic Stainless Steel Sheets" International Journal of Research in Engineering and Technology, pp. 213-217, June 2014.

[4] Debashis, M., Manjunath, A. and Parthiban, K., "Interpulse TIG Welding of Titanium Alloy(Ti-6Al$4 \mathrm{~V})$ " ,Indian Welding Journal Volume 50 pp. 56-71, October 2017.

\section{BIOGRAPHIES}

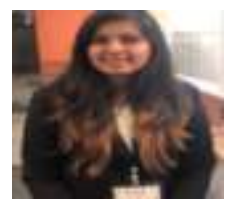

Ishika Aggarwal is pursuing second year of her Bachelor's degree in Manufacturing Processes \& Automation Engineering.

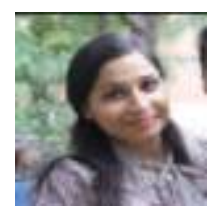

Nimeshka Faujdar is pursuing second year of her Bachelor's degree in Manufacturing Processes \& Automation Engineering.

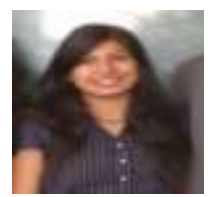

Anusua Das is pursuing second year of her Bachelor's degree in Manufacturing Processes \& Automation Engineering.

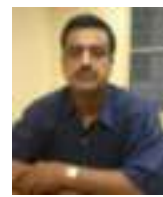

Pradeep Khanna is an Associate Professor in the Department of Manufacturing Processes \& Automation Engineering. 